\title{
Spatial Displacement of Release Point can Enhance Activity of an Attractant Pheromone Synergist of a Bark Beetle
}

\author{
Brian T. Sullivan • Kenji Mori
}

Received: 3 December 2008 /Revised: 7 October 2009 /Accepted: 14 October 2009/Published online: 10 November 2009

(C) US Government 2009

\begin{abstract}
Flight responses of the southern pine beetle, Dendroctonus frontalis Zimmermann, to widely-spaced $(>130 \mathrm{~m})$ traps baited with pine volatiles (in turpentine) and the female-produced pheromone component frontalin were enhanced when a bait containing the male pheromone component $(+)$-endo-brevicomin was attached directly to the trap. However, displacing this bait $4-16 \mathrm{~m}$ horizontally from the trap significantly increased its synergistic effect. $(+)$-endo-Brevicomin enhanced catch to the same degree when the bait was positioned either on the trap or $32 \mathrm{~m}$ away. In another experiment, pairs of frontalin/turpentinebaited traps were established with $4 \mathrm{~m}$ spacing between traps and $>100 \mathrm{~m}$ spacing between pairs. Attachment of either a racemic or $(+)$-endo-brevicomin bait to one trap of a pair caused a significant increase in catch by both traps, but catch in the trap lacking endo-brevicomin was increased more than in its endo-brevicomin-baited twin. In a third experiment, widely-spaced groups of three traps (in a line with 1 and $4 \mathrm{~m}$ spacing between the middle and outer traps) were baited uniformly with frontalin and turpentine, and the release rate of $(+)$-endo-brevicomin from the middle trap was varied across three orders of magnitude. Release rates sufficient to enhance total $D$. frontalis catch by the trio also caused relatively higher catches to occur in the outer traps than in the middle one. These experiments indicated that
\end{abstract}

B. T. Sullivan $(\bowtie)$

USDA Forest Service, Southern Research Station,

2500 Shreveport Hwy,

Pineville, LA 71360, USA

e-mail: briansullivan@fs.fed.us

K. Mori

The University of Tokyo,

Bunkyo-ku,

Tokyo 113-0023, Japan both male and female $D$. frontalis fly to and land preferentially at sources of frontalin and host odors when these are located some distance away from a source of endo-brevicomin. This behavior may have evolved in $D$. frontalis to allow host-seeking beetles to locate growing, multi-tree infestations while avoiding fully-colonized trees within these infestations. Our data demonstrate that trap spacing alone can qualitatively change the outcome of bait evaluation trials and may explain why many earlier experiments with endo-brevicomin failed to identify it as an aggregation pheromone synergist for $D$. frontalis. We believe that important aggregative functions of semiochemicals of other bark beetle species may have been similarly overlooked due to choice of experimental procedures.

Keywords Aggregation - endo-Brevicomin .

Dendroctonus frontalis . Flight behavior · Host location .

Pheromone synergist . Scolytidae $\cdot$ Semiochemical

\section{Introduction}

In studies used to identify pheromone synergists and inhibitors for bark beetles (Coleoptera: Scolytidae), candidate behavioral chemicals are typically released from the same location as an attractant, and the ability of the compounds to modify insect flight to the attractant is then measured, usually with a trap (Reeve and Strom 2004; Fettig et al. 2006). However, in natural bark beetle attacks, release points of pheromones (i.e., the individual beetle gallery entrances) are dispersed in space and time. They occur along the length of the tree stem (bole) and among adjacent, attacked trees. Furthermore, the number of new galleries accumulates with time and the composition of the pheromone blend emitted from individual beetle attacks 
changes as host colonization proceeds (Birgersson and Bergström 1989). Both males and females may contribute unique components to the pheromone blend, whereas only one sex initiates colonization (Borden 1982); hence pheromone components from the pioneer sex are emitted prior to those of the joining sex, but as multiple families accumulate at an aggregation, signaling by the pioneering and joining sexes overlaps. Additionally, either sex may produce a succession of different compounds during host colonization (Birgersson et al. 1984; Byers et al. 1984). Attacks on individual trees begin frequently at a specific height on the bole and then spread to adjacent portions over the course of a few days, and adjacent trees within infestations are typically attacked successively rather than simultaneously (Gara and Coster 1968; Berryman 1982; Schlyter et al. 1987a). Hence, at any one time, the composition and release rate of the emitted pheromone blend will vary spatially, both along the length of the infested bole as well as among adjacent, attacked trees. Pheromones arising from adjacent rather than identical points in space may send a distinctly different message to host-seeking beetles, and thus they might differently influence the location where a beetle ultimately lands. However, few studies of bark beetles have examined the effect of separating the release points of aggregation pheromone components (Byers 1987).

The southern pine beetle, Dendroctonus frontalis Zimmermann (Coleoptera: Scolytidae), is an aggressive bark beetle that is native to the southeastern United States, Arizona, Mexico, and parts of Central America (Payne 1980). Infestations typically occur across the landscape in spatially discrete, rapidly expanding "spots" in which adjacent trees are attacked in succession by beetles arriving from the surrounding forest as well as by re-emerging parent and brood adults from within the infestation (Gara 1967; Gara and Coster 1968). Aggregation is mediated by a complex of semiochemicals: initially-attacking females release the attractive pheromone component frontalin, which is enhanced synergistically both by monoterpene kairomones (particularly $\alpha$-pinene) released by the host pine and (+)-endo-brevicomin from secondarily-arriving males (Smith et al. 1993; Sullivan et al. 2007). Additionally, the female-produced pheromone component transverbenol may substitute for host monoterpenes when the latter are at low levels, and may play an important role in initiating host colonization (Renwick and Vité 1969; Payne et al. 1978a). Dendroctonus frontalis also produces several compounds (such as verbenone and myrtenol) that inhibit response to attractants, and one or more of these may function as antiaggregation pheromones for this species (Smith et al. 1993; Sullivan 2005).

There are divergent data sets on the behavioral activity of endo-brevicomin with $D$. frontalis. Studies performed with racemic endo-brevicomin indicated that this compound acts as an attractant antagonist (Vité and Renwick 1971; Payne et al. 1978a; Salom et al. 1992). In contrast, baits composed of pure (+)-endo-brevicomin (only enantiomer produced by the species) strongly enhanced attraction to combinations of frontalin and host odors (Vité et al. 1985; Sullivan et al. 2007), and led these authors to conclude that this compound was a component of the $D$. frontalis aggregation pheromone. $(+)$-endo-Brevicomin alone does not attract $D$. frontalis into traps (Sullivan et al. 2007).

Observations during trapping trials with $D$. frontalis suggested that trap spacing alone might determine whether the addition of (+)-endo-brevicomin increased, reduced, or did not alter catch in attractant-baited traps relative to attractant-only control traps (authors' unpublished data). We hypothesized that interacting pheromone components of bark beetles (i.e., synergists, antagonists) might convey unique information and elicit different behaviors when their sources are separated by a short distance (i.e., a few meters) rather than being either collocated or widely separated. We therefore performed tests to determine if point sources of endo-brevicomin could influence catch in distant traps and whether varying the distance between such point sources and attractant-baited traps could reverse the apparent activity of this pheromone component. We also performed initial studies to elucidate interactions of endo-brevicomin release rate with trap spacing and contrast the spatial dynamics of endo-brevicomin to other aggregationmediating semiochemicals for $D$. frontalis.

\section{Methods and Materials}

Location, General Design, and Materials Trapping experiments were performed by using 12-unit funnel traps (Chemtica International, San Jose, Costa Rica) placed in mature, mixed pine/hardwood stands of the Homochitto National Forest in southwestern Mississippi $\left(31.43^{\circ} \mathrm{N}\right.$, $\left.91.19^{\circ} \mathrm{W}\right)$. The pine component was dominated by loblolly pine, Pinus taeda L., interspersed with shortleaf pine, Pinus echinata Mill. Adjacent pine forests were experiencing moderate levels of $D$. frontalis infestation, but according to aerial surveys no multiple-tree beetle infestations were within $1 \mathrm{~km}$ of the trap locations. Traps were positioned $>10 \mathrm{~m}$ from the nearest pine and suspended (with the bottom of the trap cup 1-1.5 $\mathrm{m}$ above the ground) from vertical standards consisting of $1.7 \mathrm{~cm}$ dia. pieces of electrical conduit staked into the ground. Trap cups contained several centimeters of aqueous propylene glycol to preserve captured insects, and catch was collected at intervals of 6-18 d (longer intervals were used during periods when flying beetles were less abundant). Frontalin baits consisted of a pair of capped $400 \mu$ l-capacity LDPE 
microcentrifuge tubes each loaded with $200-300 \mu$ racemic frontalin $[>95 \%$ chemical purity (contaminants with no known behavioral activity), Chemtica International]. Turpentine baits consisted of a single $250 \mathrm{ml}$-capacity brown glass bottle with a piece of $1 \mathrm{~cm}$ dia. cotton dental wick immersed in the liquid (200-250 $\mathrm{ml}$, steam distilled from P. taeda; Hercules Inc., Brunswick, GA, USA) and protruding $2.5 \mathrm{~cm}$ through the cap. endo-Brevicomin was released either from glass capillaries with one heat-sealed end or from open, $100 \mu$ l-capacity glass autosampler vial inserts; these were secured open-end-up inside of an uncapped, inverted 4 or 8 ml-capacity glass screw-cap vial (Table 1). The capillaries and autosampler vial inserts were secured in the vial with a silicone GC septum that was pressed sideways into the vial mouth; the sealed end of each capillary (or the tapered tip of each insert) was inserted into a pinhole in the interior-facing edge of the septum. (+)endo-Brevicomin was synthesized as described elsewhere (Sullivan et al. 2007) and was $>99 \%$ enantiomerically and 95\% chemically pure by GC (contaminants with no known behavioral activity). Racemic endo-brevicomin [PheroTech (now ConTech Inc.), Delta, BC, Canada] was 95\% chemically pure $(<1 \%$ exo-brevicomin contamination). Bait release rates were measured in a fume hood at $23 \pm 2^{\circ} \mathrm{C}$, either gravimetrically for turpentine $(7 \mathrm{~g} / \mathrm{d})$ and frontalin $(5 \mathrm{mg} / \mathrm{d})$ or by volume loss for endo-brevicomin (Table 1). Frontalin and endo-brevicomin baits were attached at the fourth funnel from the bottom of the trap, whereas the turpentine bottle was placed within the funnel immediately below the trap top to protect the wick from rain. During experiments, pines adjacent to traps were checked regularly for the presence of pitch tubes and other evidence of $D$. frontalis attack. If attacked pines were apparently not under mass attack (Payne 1980), traps were moved an additional 10-20 $\mathrm{m}$ from these trees thereby stopping further attacks; if a mass attack was observed (as occurred twice), traps were moved at least $100 \mathrm{~m}$ away. In both cases, data from the moved trap was used in the analyses.
Experiment 1: Displacement of (+)-endo-Brevicomin Bait from an Attractant-Baited Trap Single funnel traps were spaced $>130 \mathrm{~m}$ apart, baited uniformly with frontalin and turpentine, and assigned one of six experimental treatments (Fig. 1a): A single (+)-endo-brevicomin bait was either attached directly to the trap (i.e., at $0 \mathrm{~m}$ ), or positioned 4,8 , 16 , or $32 \mathrm{~m}$ away, or no endo-brevicomin bait was assigned to the trap (in this case the closest source of endobrevicomin was associated with adjacent traps and thus was $>100 \mathrm{~m}$ away). Three lines of six traps each were established, and the six treatments were assigned initially at random to the six traps of each line and then re-randomized without replacement to any previous position for each of six successive trap collections. Thus, the experimental design was three complete Latin squares with each square consisting of six traps (columns) and six successive trapping intervals (rows). The displaced endo-brevicomin release devices were suspended $1.5 \mathrm{~m}$ above the ground on plastic garden stakes and the direction that each release device was located relative to its treatment trap $\left(0^{\circ}, 60^{\circ}\right.$, $120^{\circ}, 180^{\circ}, 240^{\circ}$, or $300^{\circ}$ from north) was assigned at random and without duplication among the six traps of each line. This directional assignment remained the same for each trap position for the duration of the experiment. The experiment was conducted 8 February-12 April 2006. Trap catches of $D$. frontalis were cube root transformed and analyzed with a mixed-model ANOVA in which treatment, date, and treatment by date effects were considered fixed, whereas square, trap within square, and treatment by square effects were regarded as random (SAS 9.0, SAS Institute Inc., Cary, NC). The cube-root transformation was used for analysis of this and all following ANOVAs of total $D$. frontalis catches because it was generally better at normalizing residuals than the weaker square root or the stronger $\log _{10}$ transformation (based on examination of residual plots), and in all comparisons the residuals from the transformed data sets did not fail the Kolmogorov-Smirnov test for a normal distribution $(\alpha=0.05)$. Treatment means

Table 1 Construction and elution rate of endo-brevicomin release devices ${ }^{\mathrm{a}}$

Glass insert/capillary characteristics

\begin{tabular}{lccccc}
\cline { 2 - 5 } Experiment number (release rate) & Diameter (i.d.) & Length & Height filled & Number per device & Elution rate ${ }^{\mathrm{c}}(\mathrm{mg} / \mathrm{d} \pm \mathrm{s.d}$ ) \\
\hline $1,2^{\mathrm{b}}, 4$ & $1.2 \mathrm{~mm}$ & $20 \mathrm{~mm}$ & $10 \mathrm{~mm}$ & 1 & $0.23 \pm 0.01$ \\
3 (low rate) & $0.6 \mathrm{~mm}$ & $32 \mathrm{~mm}$ & $10 \mathrm{~mm}$ & 1 & $0.045 \pm 0.007$ \\
3 (medium rate) & $1.2 \mathrm{~mm}$ & $32 \mathrm{~mm}$ & $10 \mathrm{~mm}$ & 3 & $0.52 \pm 0.03$ \\
3 (high rate) & $3.7 \mathrm{~mm}$ & $30 \mathrm{~mm}$ & $8 \mathrm{~mm}$ & 3 & $2.8 \pm 0.6$ \\
\hline
\end{tabular}

\footnotetext{
${ }^{\text {a }}$ Each device consisted of 1-3 glass autosampler vial inserts or glass capillaries secured open-end-up inside of an inverted, uncapped $4 \mathrm{ml}$ (8 ml for the high release rate device) capacity screw-capped vial.

${ }^{\mathrm{b}}$ In experiment 2, a single device was used for (+)-endo-brevicomin, but two devices were used for racemic endo-brevicomin.

${ }^{\mathrm{c}}$ Measured in a fume hood at $23 \pm 2^{\circ} \mathrm{C}(N=3)$.
} 
Fig. 1 Trap and bait arrangements for experiments 1-4. Rectangles represent release devices of either frontalin $(\mathrm{F})$, turpentine $(\mathrm{T})$, $(+)$-endo-brevicomin $(+\mathrm{B})$, racemic endo-brevicomin $( \pm \mathrm{B})$, or an experimentally variable bait (shaded X and Y). For the 4, 8, 16 , and $32 \mathrm{~m}$-distances in experiment 1 , the " $+\mathrm{B}$ " release device was attached to the top of a plastic garden stake; for the $>100 \mathrm{~m}$ treatment, no $+\mathrm{B}$ device was assigned to the trap and the closest such device was associated with an adjacent treatment. Otherwise, release devices were attached directly to traps
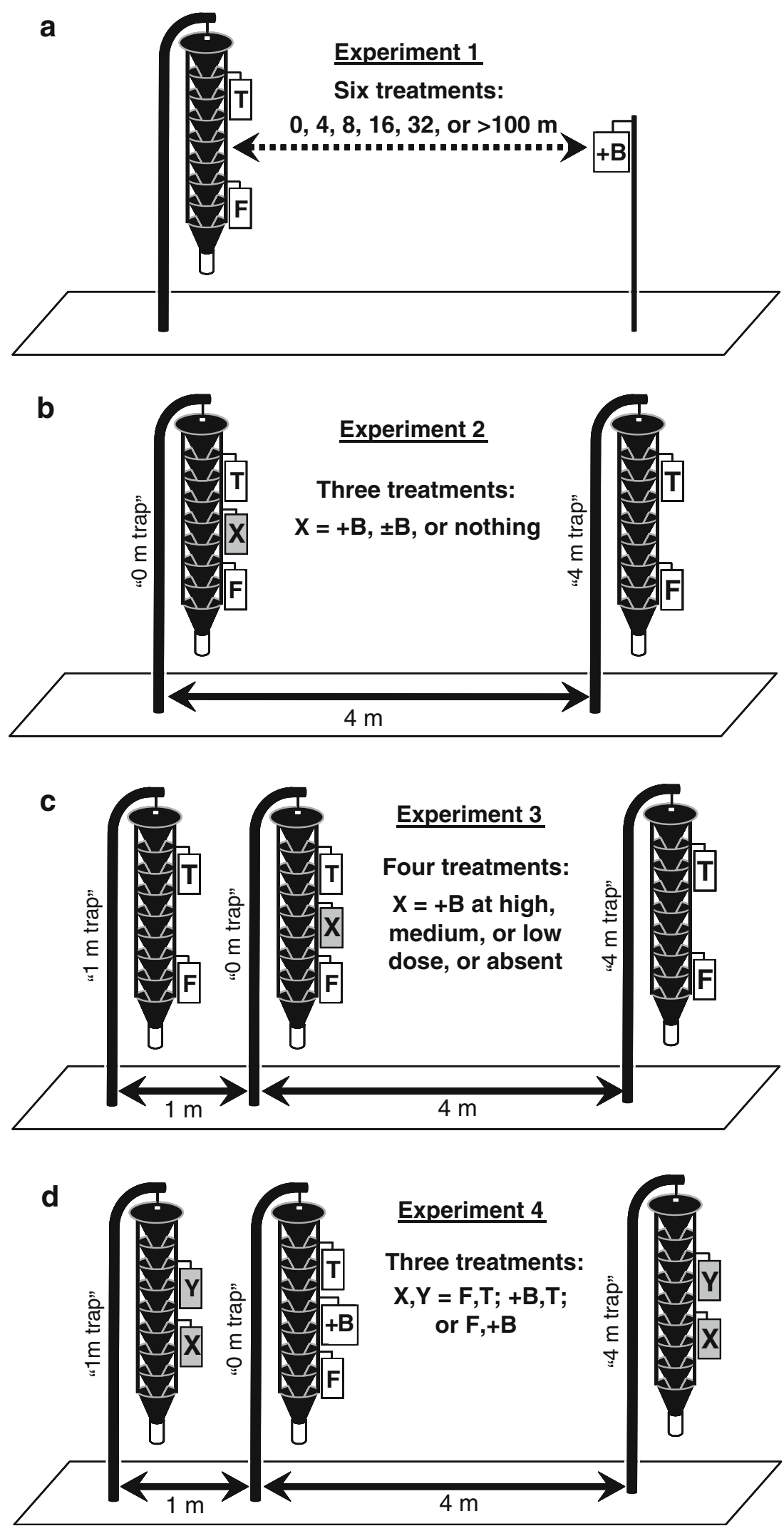
were compared by using Tukey's test for all pairwise comparisons $(\alpha=0.05)$ with treatment by square as the error term. In this and the other trapping experiments, catches for some traps and intervals were very low or zero, hence use of the above ANOVA for analysis of treatment effects on sex ratio was not possible due to the excessive numbers of missing values and/or the highly non-normal distributions of residuals. Therefore, the proportion of female $D$. frontalis trapped in each treatment was pooled within a square and subjected to a two-way ANOVA with square and treatment as factors. Proportions of females trapped were not transformed for this or other experiments since the pooled data never failed the Kolmogorov-Smirnov test $(\alpha=0.05)$.

Experiment 2: Pairs of Adjacent Traps Differing in endoBrevicomin Pairs of funnel traps spaced $4 \mathrm{~m}$ apart and baited identically with frontalin and turpentine were established at locations separated by $>100 \mathrm{~m}$ (Fig. 1b). One trap of each pair (the " $0 \mathrm{~m}$ trap;" chosen by a coin toss), received either a single (+)-endo-brevicomin bait, two racemic endo-brevicomin baits, or no additional bait (three experimental treatments). The opposite trap (the " $4 \mathrm{~m}$ trap") received no additional bait. Four lines, each with three trap pair locations, were established, and the treatments were assigned initially at random to the three pairs of each line and then re-randomized without replacement to any previous pair for each of three successive trap collections. Thus, the experimental design was four complete Latin squares with each square consisting of three adjacent trap pairs (columns) and three successive trapping intervals (rows). The experiment was run 13 December 2005-17 January 2006. The summed $D$. frontalis catch per trap pair $\left(\Sigma_{\mathrm{x}}=\mathrm{X}_{4 \mathrm{~m}}+\mathrm{X}_{0 \mathrm{~m}}\right.$, transformed $\left.\sqrt{3} \Sigma_{\mathrm{x}}\right)$ and the difference in catch $\left(D_{x}=X_{4 m}-X_{0 m}\right.$, transformed $\left.{ }^{3} \sqrt{ } D_{x}\right)$, were analyzed with the mixed-model ANOVA of experiment 1. Treatment effects on the proportion of females trapped per pair and the difference in proportion of females between members of each pair were analyzed with a two-way ANOVA (as in experiment 1). Additionally, beetle responses to the two traps of each pair $\left(\mathrm{X}_{4 \mathrm{~m}}\right.$ vs. $\left.\mathrm{X}_{0 \mathrm{~m}}\right)$ were compared within each treatment by a paired $t$-test $(\alpha=0.05)$.

Experiment 3: Trios of Adjacent Traps with Varying endoBrevicomin Release Rate At locations separated by $>100 \mathrm{~m}$, groups of three traps were erected in a straight line with the outside traps spaced $1 \mathrm{~m}$ and $4 \mathrm{~m}$ away from the middle trap (Fig. 1c). The outside traps were erected first, and then the location of the middle trap respective to either outside trap (i.e., the assignment of $4 \mathrm{~m}$ and $1 \mathrm{~m}$-distant traps) was chosen by a coin toss. All three traps were baited with frontalin and turpentine, and the middle trap (the " $0 \mathrm{~m}$ trap") either received no additional bait or was baited additionally with a device releasing either a low, medium, or high rate
(Table 1) of (+)-endo-brevicomin (four experimental treatments). Two lines, each with four trap trio locations, were established, and the treatments were assigned initially at random to the four trios of each line and then re-randomized without replacement to any previous trio for each of four successive trap collections. After these initial four collections (after every treatment had been at every trio location once), the middle trap was moved $3 \mathrm{~m}$ in order to reverse the designation of the 1- and 4 m-distant traps within each trio. Then treatment assignments were re-randomized among trios within lines, and a second set of four successive collections was performed similar to the first. Thus, the experimental design was four complete Latin squares with each square consisting of four adjacent trap trios (columns) and four successive trapping intervals (rows). The experiment was run 16 August-23 October 2005. Total catch of $D$. frontalis per trap trio $\left(\Sigma_{\mathrm{x}}=\mathrm{X}_{4 \mathrm{~m}}+\mathrm{X}_{1 \mathrm{~m}}+\mathrm{X}_{0 \mathrm{~m}}\right.$; transformed $\left.{ }^{3} \sqrt{\Sigma_{\mathrm{x}}}\right)$ as well as the differences in catch between the outside and middle traps $\left(D_{1}=X_{4 m}-X_{0 m}, D_{2}=X_{1 m}-X_{0 m}\right.$; transformed $\left.{ }^{3} \sqrt{D_{x}}\right)$ were analyzed with a mixed model ANOVA in which treatment and date within square were considered fixed, and square, trio within square, and treatment by square were regarded as random effects (SAS 9.0). Date was included in the model as a fixed effect nested within square to account for replication of squares in time. Tukey's all-pairwise comparisons $(\alpha=0.05)$ utilized treatment by square as the error term. Treatment effects on the proportion of females trapped per trio, and the differences in proportion of females between the outer and middle traps, were analyzed with a two-way ANOVA (as in experiment 1).

Experiment 4: Trios of Adjacent Traps with Variable Baits Trap trios were established identically as in experiment 3 , however, the $0 \mathrm{~m}$ trap was baited consistently with frontalin, turpentine, and (+)-endo-brevicomin, whereas the 4- and $1 \mathrm{~m}$-distant traps were both baited identically with just two of these bait components and thus lacked one of (+)-endo-brevicomin, frontalin, or turpentine (i.e., three treatments, Fig. 1d). Three lines, each with three trap trio locations were established, and treatments were assigned initially at random to the three trios of each line and then rerandomized without replacement to any previous position for each of three successive trap collections. Thus, the experimental design was three complete Latin squares, with each square consisting of three adjacent trap trios (columns) and three successive trapping intervals (rows). The experiment was run 17 October-14 November 2005. Differences in catch between the outside and middle traps $\left(D_{1}=X_{4 m}\right.$ $\mathrm{X}_{0 \mathrm{~m}}, \mathrm{D}_{2}=\mathrm{X}_{1 \mathrm{~m}}-\mathrm{X}_{0 \mathrm{~m}}$; transformed ${ }^{3} \sqrt{\mathrm{D}_{\mathrm{x}}}$ ) were compared among treatments by using the mixed-model ANOVA of experiment 1. Differences in proportion of females trapped between the outer and middle traps were subjected to a twoway ANOVA (as in experiment 1). 
A corollary data set was collected to determine whether catch in the outside and middle traps differed when all three traps in each trio were baited identically. Trios as described above were established at 14 different sites, all three baits were placed at all three traps, and catch during a single 7$18 \mathrm{~d}$ interval was collected from each on 7 November 2005-17 January 2006. For all bait configurations, the transformed differences in catch between the outside and middle traps $\left(\sqrt[3]{ } \mathrm{D}_{1}, \sqrt[3]{ } \mathrm{D}_{2}\right)$ were each tested against the null hypothesis of equality to zero with a one-sample $t$-test (twotailed, $\alpha=0.05$ ).

\section{Results}

Experiment 1: Displacement of (+)-endo-Brevicomin Bait from an Attractant-Baited Trap Catch of D. frontalis in traps baited with frontalin and turpentine was significantly influenced by trap distance from a (+)-endo-brevicomin release device $(F=85.8 ; \mathrm{df}=5,10 ; P<0.001)$. Traps caught significantly more beetles when the $(+)$-endobrevicomin releaser was $0-32 \mathrm{~m}$ distant rather than $>100 \mathrm{~m}$ away (Fig. 2). Furthermore, catch was significantly greater when the $(+)$-endo-brevicomin release device was 4,8 , or $16 \mathrm{~m}$ away from the trap rather than attached directly to it. Distance of the endo-brevicomin releaser from the trap did not significantly alter the

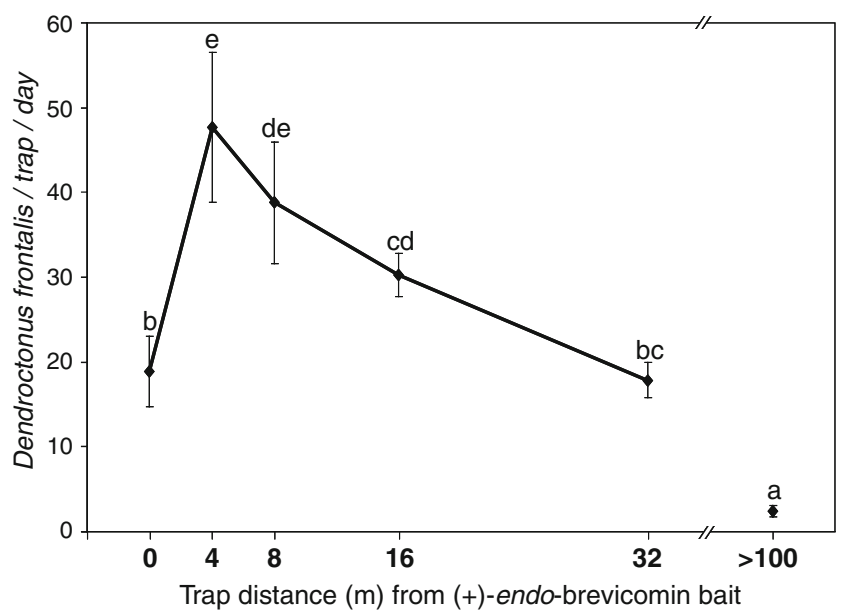

Fig. 2 Experiment 1: Mean ( \pm s.e.) daily catch of Dendroctonus frontalis in individual multiple-funnel traps baited with frontalin and turpentine. Traps were positioned $>130 \mathrm{~m}$ apart, and each trap either had a single release device of $(+)$-endo-brevicomin placed a specified distance $(0,4,8,16,32 \mathrm{~m})$ away from it or had no $(+)$-endobrevicomin bait assigned [i.e., the closest $(+)$-endo-brevicomin bait was in an adjacent treatment or $>100 \mathrm{~m}$ away)]. Means associated with the same letter were not significantly different (Tukey test on cube root transformed data, $\alpha=0.05$ ). Means and s.e.'s were calculated from the untransformed data with six observations averaged within each Latin square $(N=3)$ proportion $(0.40 \pm 0.01$, mean \pm s.d. $)$ of females responding $(F=0.37 ; \mathrm{df}=5,10 ; P=0.86)$.

Experiment 2: Pairs of Adjacent Traps Differing in endoBrevicomin Pairs of traps spaced $4 \mathrm{~m}$ apart and baited identically with frontalin and turpentine caught significantly more $D$. frontalis when one of the two traps was baited additionally with either $(+)$ - or racemic endobrevicomin $(F=94.6 ; \mathrm{df}=2,6 ; P<0.001$; Fig. 3). Trap pairs with either $(+)$ - or racemic endo-brevicomin did not differ significantly in total catch (Tukey test, $P>0.05$ ). Furthermore, the disparity in catch between traps within pairs was significantly altered by the addition of either $(+)$ - or racemic endo-brevicomin to one of the traps $(F=$ 26.0; $\mathrm{df}=2,6 ; P=0.001)$. Within endo-brevicomin-treated trap pairs, the trap that lacked endo-brevicomin caught significantly more beetles than its endo-brevicomin-baited twin [for $(+)$-endo-brevicomin: $t=3.78, \mathrm{df}=11, P=0.003$; for racemic endo-brevicomin: $t=3.2, \mathrm{df}=11, P=0.008]$, whereas there was no significant difference in catch between traps within pairs when endo-brevicomin was not added to either of the two traps $(t=0.86, \mathrm{df}=11, P=$ $0.41)$ (Fig. 3). There were no significant treatment effects on the proportions of females trapped [either total catch per trap pair $(F=0.38 ; \mathrm{df}=2,6 ; P=0.70)$ or difference between the traps in proportion of females caught $(F=$ $0.71 ; \mathrm{df}=2,6 ; P=0.53)]$. The overall proportion of females trapped was $0.42 \pm 0.03$ (mean \pm s.d.).

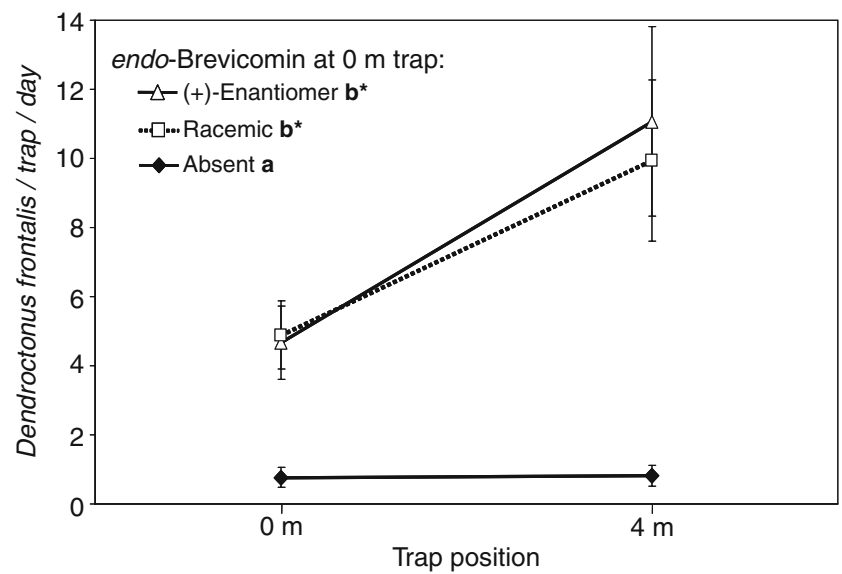

Fig. 3 Experiment 2: Mean ( \pm s.e.) daily catch of Dendroctonus frontalis in traps arranged in pairs with $4 \mathrm{~m}$ spacing between traps and $>100 \mathrm{~m}$ spacing among pairs. All traps were baited with frontalin and turpentine, and one randomly-chosen trap per pair (the " $0 \mathrm{~m}$ trap") was baited additionally with racemic endo-brevicomin, (+)-endobrevicomin, or nothing. Treatment names in legend inset associated with the same letter did not differ significantly in summed beetle catch per pair (Tukey test on cube root transformed data, $\alpha=0.05$ ); those with an asterisk had a significant difference in catch between the two traps within the pair (paired $t$-test; $\alpha=0.05$ ). Means and s.e.'s were calculated from the untransformed data with three observations averaged within each Latin square $(N=4)$ 
Experiment 3: Trios of Adjacent Traps with Varying endoBrevicomin Release Rate Total catch of $D$. frontalis by trios of frontalin/turpentine-baited traps was significantly affected by the rate of $(+)$-endo-brevicomin released from the middle trap $(F=34.3 ; \mathrm{df}=3,9 ; P<0.001$; Table 2$)$. The disparity in catch between the outer and middle traps was likewise influenced by the release rate of (+)-endo-brevicomin (for $\mathrm{X}_{4 \mathrm{~m}}-\mathrm{X}_{0 \mathrm{~m}}: F=10.3 ; \mathrm{df}=3,9 ; P=0.003$; for $\mathrm{X}_{1 \mathrm{~m}}-\mathrm{X}_{0 \mathrm{~m}}: F=16.9$; $\mathrm{df}=3,9 ; P<0.001)$. In general, increasing the release rate of $(+)$-endo-brevicomin at the middle trap enhanced total catch by the trios, and it caused a relatively greater increase in catch at the two outer traps than at the middle trap (Table 2). Release rate of $(+)$-endo-brevicomin from the middle trap had no effect on the proportions of females trapped [either total catch per trio of traps $(F=0.73 ; \mathrm{df}=3,9 ; P=0.56)$ or difference between outer and middle traps $(F<0.28 ; \mathrm{df}=3,9$; $P>0.84)$ ]. The overall proportion of females trapped was $0.48 \pm 0.04$ (mean \pm s.d.).

Experiment 4: Trios of Adjacent Traps with Variable Baits The disparity in catch between the outer and middle traps of trap trios was significantly influenced by altering the bait component that was removed in the outer trap treatments (for $\mathrm{X}_{4 \mathrm{~m}}-\mathrm{X}_{0 \mathrm{~m}}: F=13.0 ; \mathrm{df}=2,4 ; P=0.018$; for $\left.\mathrm{X}_{1 \mathrm{~m}}-\mathrm{X}_{0 \mathrm{~m}}: F=8.41 ; \mathrm{df}=2,4 ; \quad P=0.037\right)$. When $(+)$-endobrevicomin was absent from the outer traps, catch in each outer trap was greater than in the middle trap, whereas the reverse occurred when frontalin was absent (Table 3). The arrangement of baits had no significant effect on the difference in proportions of females trapped by the outer and middle traps $(F<2.36 ; \mathrm{df}=2,4 ; P>0.21)$. The overall proportion of females trapped was $0.45 \pm 0.06$ (mean \pm s.d.). When trap trios were established with all three baits at all three traps (Table 3, corollary data set), catch in the outer traps did not differ from catch in the middle trap (for $\mathrm{X}_{4 \mathrm{~m}^{-}}$ $\mathrm{X}_{0 \mathrm{~m}}: t=0.099 ; \mathrm{df}=13 ; P=0.92 ;$ for $\mathrm{X}_{1 \mathrm{~m}}-\mathrm{X}_{0 \mathrm{~m}}: t=0.127$; $\mathrm{df}=13 ; P=0.90)$.

\section{Discussion}

Horizontal displacement of the release point of a single release rate of the male-produced pheromone component endo-brevicomin significantly enhanced its synergistic effect on $D$. frontalis attraction to sources of femaleproduced frontalin and host odors (experiment 1, Fig. 2). We are not aware of previous reports in which separation of the release points of synergistic insect pheromone components caused enhanced attraction. Incremental separation of a pair of traps each baited with different synergistic components of the aggregation pheromone of the western pine beetle, Dendroctonus brevicomis LeConte, caused a rapid, logarithmic decline in attraction of this bark beetle (Byers 1987). For two moth species [cabbage looper, Trichoplusia ni (Hübner), and the spotted stem borer, Chilo partellus (Swinhoe)], separation of the release points of two sex pheromone components by mere centimeters significantly reduced the percentage of males reaching the sources (Linn and Gaston 1981; Lux et al. 1994).

Of the three major components of the aggregation attractant for $D$. frontalis (i.e., frontalin, (+)-endo-brevico-

Table 2 Experiment 3. Effect of varying release rate of (+)-endo-brevicomin on catch of Dendroctonus frontalis by trios of adjacent funnel traps ${ }^{\mathrm{a}}$

\begin{tabular}{|c|c|c|c|c|c|}
\hline $\begin{array}{l}\text { Release rate of }(+) \text {-endo- } \\
\text { brevicomin at } 0 \mathrm{~m} \text { trap }^{\mathrm{b}}\end{array}$ & $\begin{array}{l}\text { Trap position } \\
\text { within trio }\end{array}$ & $\begin{array}{l}\text { Catch } \\
(\text { No./trap/d) })^{c}\end{array}$ & $\begin{array}{l}\text { Total catch } \\
(\text { No./trio/d })^{\mathrm{c}, \mathrm{d}}\end{array}$ & $\begin{array}{l}\text { Difference in catch between } \\
4 \mathrm{~m} \text { and } 0 \mathrm{~m} \operatorname{trap}^{\mathrm{c}, \mathrm{d}}\end{array}$ & $\begin{array}{l}\text { Difference in catch between } \\
1 \mathrm{~m} \text { and } 0 \mathrm{~m} \operatorname{trap}^{\mathrm{c}, \mathrm{d}}\end{array}$ \\
\hline Absent & $\begin{array}{ll}0 & \mathrm{~m} \\
1 & \mathrm{~m} \\
4 & \mathrm{~m}\end{array}$ & $\begin{array}{l}0.70 \pm 0.35 \\
0.70 \pm 0.40 \\
1.03 \pm 0.71\end{array}$ & $2.42 \pm 1.46 \mathrm{a}$ & $0.33 \pm 0.37 \mathrm{ab}$ & $0.00 \pm 0.05 \mathrm{a}$ \\
\hline Low & $\begin{array}{ll}0 & \mathrm{~m} \\
1 & \mathrm{~m} \\
4 & \mathrm{~m}\end{array}$ & $\begin{array}{l}0.94 \pm 0.26 \\
1.02 \pm 0.29 \\
1.16 \pm 0.26\end{array}$ & $3.11 \pm 0.79 \mathrm{a}$ & $0.22 \pm 0.16 \mathrm{a}$ & $0.08 \pm 0.04 \mathrm{a}$ \\
\hline Medium & $\begin{array}{ll}0 & \mathrm{~m} \\
1 & \mathrm{~m} \\
4 & \mathrm{~m}\end{array}$ & $\begin{array}{l}5.02 \pm 1.45 \\
6.71 \pm 1.74 \\
7.67 \pm 1.63\end{array}$ & $19.4 \pm 4.71 \mathrm{~b}$ & $2.65 \pm 0.46 b c$ & $1.68 \pm 0.46 b$ \\
\hline High & $\begin{array}{ll}0 & \mathrm{~m} \\
1 & \mathrm{~m} \\
4 & \mathrm{~m}\end{array}$ & $\begin{array}{r}6.49 \pm 1.83 \\
9.80 \pm 2.88 \\
12.39 \pm 4.06\end{array}$ & $28.7 \pm 8.63 b$ & $5.90 \pm 2.53 \mathrm{c}$ & $3.30 \pm 1.11 \mathrm{~b}$ \\
\hline
\end{tabular}

\footnotetext{
${ }^{\text {a }}$ Three traps were arranged in a straight line with the outer traps located either $1 \mathrm{~m}$ or $4 \mathrm{~m}$ from the middle ("0 $\mathrm{m}$ ") trap. All three traps were baited with frontalin and turpentine, and the release rate of $(+)$-endo-brevicomin from the $0 \mathrm{~m}$ trap was varied.

${ }^{\mathrm{b}}$ See Table 1.

${ }^{\mathrm{c}}$ Mean \pm s.e. Standard errors were calculated for untransformed data with four observations averaged within each Latin square $(N=4)$.

${ }^{\mathrm{d}}$ Means within a column associated with the same letter were not significantly different (Tukey test on cube root transformed data, $\alpha=0.05$ ).
} 
Table 3 Experiment 4: Effect of varying bait assignment on catch of Dendroctonus frontalis by trios of adjacent funnel traps ${ }^{\mathrm{a}}$

\begin{tabular}{|c|c|c|c|c|}
\hline $\begin{array}{l}\text { Bait component removed } \\
\text { from } 1 \mathrm{~m} \text { and } 4 \mathrm{~m} \text { traps }^{\mathrm{b}}\end{array}$ & $\begin{array}{l}\text { Trap position } \\
\text { within trio }\end{array}$ & $\begin{array}{l}\text { Catch } \\
\left(\text { No./trap/d) }{ }^{\mathrm{c}}\right.\end{array}$ & $\begin{array}{l}\text { Difference in catch between } \\
4 \mathrm{~m} \text { and } 0 \mathrm{~m} \text { trap }^{\mathrm{c}, \mathrm{d}}\end{array}$ & $\begin{array}{l}\text { Difference in catch between } \\
1 \mathrm{~m} \text { and } 0 \mathrm{~m} \text { trap }\end{array}$ \\
\hline \multicolumn{5}{|l|}{ Compared treatments ${ }^{\mathrm{e}}$} \\
\hline$(+)$-endo-Brevicomin & $\begin{array}{ll}0 & \mathrm{~m} \\
1 & \mathrm{~m} \\
4 & \mathrm{~m}\end{array}$ & $\begin{array}{l}2.98 \pm 0.89 \\
3.73 \pm 1.23 \\
5.12 \pm 1.91\end{array}$ & $2.14 \pm 1.13 b^{*}$ & $0.76 \pm 0.44 b^{*}$ \\
\hline Frontalin & $\begin{array}{ll}0 & \mathrm{~m} \\
1 & \mathrm{~m} \\
4 & \mathrm{~m}\end{array}$ & $\begin{array}{l}1.54 \pm 0.60 \\
0.40 \pm 0.16 \\
0.14 \pm 0.05\end{array}$ & $-1.40 \pm 0.55 \mathrm{a}^{*}$ & $-1.14 \pm 0.44 \mathrm{a}^{*}$ \\
\hline Turpentine & $\begin{array}{ll}0 & \mathrm{~m} \\
1 & \mathrm{~m} \\
4 & \mathrm{~m}\end{array}$ & $\begin{array}{l}1.69 \pm 0.39 \\
1.62 \pm 0.46 \\
1.19 \pm 0.33\end{array}$ & $-0.50 \pm 0.34 \mathrm{a}$ & $-0.07 \pm 0.25 \mathrm{ab}$ \\
\hline \multicolumn{5}{|l|}{ Corollary data set ${ }^{\mathrm{f}}$} \\
\hline None (all three baits at all three traps) & $\begin{array}{ll}0 & \mathrm{~m} \\
1 & \mathrm{~m} \\
4 & \mathrm{~m}\end{array}$ & $\begin{array}{l}7.24 \pm 1.68 \\
7.64 \pm 1.96 \\
7.69 \pm 2.09\end{array}$ & $0.44 \pm 0.81$ & $0.40 \pm 0.71$ \\
\hline
\end{tabular}

${ }^{\text {a }}$ Three traps were arranged in a straight line with the outer traps located either $1 \mathrm{~m}$ or $4 \mathrm{~m}$ from the middle (" $0 \mathrm{~m}$ ") trap. The $0 \mathrm{~m}$ trap received all three bait components, whereas the 1 and 4 m traps were baited identically and each lacked a single component.

${ }^{\mathrm{b}}$ See Table 1.

${ }^{\mathrm{c}}$ Mean \pm s.e.

${ }^{\mathrm{d}}$ Means within a column associated with the same letter were not significantly different (Tukey test on cube root transformed data, $\alpha=0.05$ ). Asterisk denotes rejection of the hypothesis that the difference equaled zero (one sample $t$-test, $\mathrm{df}=8, P<0.05$ )

${ }^{\mathrm{e}}$ Treatments compared in a Latin square experimental design. Means and s.e.'s calculated from untransformed data with three observations averaged within each Latin square $(N=3)$

${ }^{\mathrm{f}}$ Descriptive data set collected separately from 14 trap trios with all three traps baited identically with all three bait components. Data excluded from statistical comparisons among treatments. Means and s.e.'s calculated with each trio as the unit of replication $(N=14)$

min, and host monoterpenes; Sullivan et al. 2007), only (+)endo-brevicomin and frontalin appeared to mediate beetle discrimination among closely-spaced traps (experiment 4, Table 3). Beetle captures were concentrated in traps that were relatively closer to a frontalin source, but relatively more distant from a (+)-endo-brevicomin source (Table 3). This tendency of $D$. frontalis to be trapped close to the source of frontalin is consistent with its proposed function as a releaser of landing behavior for this species (Hughes 1976) and likely reflects the general tendency of bark beetle aggregation pheromones to concentrate beetle flight and landings near their release point (Coster and Gara 1968; Tilden et al. 1979; Laidlaw and Wieser 2003). In contrast, endo-brevicomin does not appear to direct landings close to its point of release. Although its release rate was varied across three orders of magnitude, catch was never higher in a trap amended with $(+)$-endo-brevicomin than in unamended traps positioned 1 and $4 \mathrm{~m}$ distant (experiment 3 , Table 2), and the synergistic effect of (+)-endo-brevicomin was the same whether the release device was placed directly on a frontalin/turpentine-baited trap or $32 \mathrm{~m}$ away from it (Fig. 2). Thus, endo-brevicomin appears to function as a synergist on an area-wide scale, enhancing attraction and landing of beetles to any sources of frontalin/host odors within a radius of tens of meters.
With the exception of the highest release rate used in experiment 3, the endo-brevicomin release rates in our experiments (Table 1) were within the range that we estimate is produced by a single pine undergoing mass attack by $D$. frontalis. Based on calculations and data reported in Coulson et al. (1976) and Fargo et al. (1978), approximately $0.4-1.8 \times 10^{3} \mathrm{D}$. frontalis pairs per day infest a $25-40 \mathrm{~cm}$ diameter loblolly pine in the first $4 \mathrm{~d}$ following initiation of mass attack, whereas an individual male $D$. frontalis paired for $<1 \mathrm{~d}$ with a female produces $291 \pm 55 \mathrm{ng}$ endo-brevicomin in an $18 \pm 2 \mathrm{hr}$ period (Sullivan et al. 2007). Thus, during the first days of a mass attack, we conservatively estimate that a single mass-attacked tree yields $0.12-0.52 \mathrm{mg}$ endo-brevicomin/d. Our estimate is also in agreement with that of Browne et al. (1979) for the release rate of frontalin (the male-produced bicyclic acetal aggregation pheromone component of the sibling species, D. brevicomis). These authors reported the collection of 0.4 and $3.3 \mu \mathrm{g}$ frontalin per $\mathrm{m}$ of bole per $\mathrm{hr}$ from two different infested ponderosa pines. When extrapolated over $24 \mathrm{hr}$ and $5 \mathrm{~m}$ of infested bole their measurement represents a release rate of 0.048 and $0.40 \mathrm{mg} / \mathrm{d} /$ tree. Since stand densities recommended for host species of $D$. frontalis produce an average $4-10 \mathrm{~m}$ spacing among trees of susceptible ages (Nebeker et al. 1985), we deduce that endo-brevicomin 
arising from a single infested tree could synergize attraction of beetles to attacks on potentially dozens or hundreds of neighboring trees.

Additionally, at an adequately high release of endobrevicomin, this synergy would evidently be stronger at adjacent trees than the tree of pheromone origin. Thus, elevated $(+)$-endo-brevicomin concentrations associated with high densities of beetle pairs should disproportionately enhance beetle responses to neighboring trees that are in the early stages of colonization by solitary, frontalin-releasing females. Pheromones are believed to play an important role in shifting the focus of bark beetle attack from fullycolonized trees to neighboring trees that are either in the initial stages of colonization or not yet attacked (Renwick and Vité 1970; Borden 1989). Furthermore, synchronization of such host "switching" by the beetle population is evidently critical to the sustained growth of $D$. frontalis infestations (Gara and Coster 1968). Several authors have proposed that host switching in D. frontalis and other bark beetles is mediated by the compounded effects of pheromones of opposing activities: long-range attractants from both the old and new attack foci draw beetles into the area while simultaneously short-range inhibitors deter landings on old attack foci (Johnson and Coster 1978; Payne 1980; Berryman 1982; Schlyter et al. 1987a). In contrast, endobrevicomin may promote host switching by $D$. frontalis through a single principle, namely, the disproportionate enhancement of attraction to relatively more distant sources of frontalin/host odors.

Bark beetle semiochemicals have been classified as either synergists or inhibitors typically with "attractant-challenge"type experiments in which a bait of undetermined activity is attached to a randomly-selected, attractant-baited trap, and catch is compared to a simultaneously-operated, attractantonly control trap (Reeve and Strom 2004; Fettig et al. 2006). If catch in the challenged trap is significantly lower than the control, the test bait is concluded to be inhibitory; if catch is significantly higher than the control, the test bait is concluded to be a synergist or attraction enhancer (Payne et al. 1978a; Bedard et al. 1980; Bakke 1981; Pureswaran and Borden 2004; Sullivan 2005). Our data demonstrate how such attractant-challenge tests might generate misleading or inconsistent conclusions regarding the activity of a compound. In experiment 2 (Fig. 3), catch in the randomly chosen, endo-brevicomin-challenged trap of a pair was significantly lower than in its $4 \mathrm{~m}$-distant, attractant-only baited twin (the latter being equivalent to a control in an attractant-challenge type experiment employing $4 \mathrm{~m}$ trap spacing). Thus, according to the traditional interpretation of such data, endo-brevicomin inhibited catch at the experimental trap. However, since catch by both traps of the pair was much lower in the absence of endo-brevicomin, the difference within the pair was apparently due to greater enhancement of catch in the control trap than the challenged trap and not to inhibition in the challenged trap.

Theoretically, any synergist possessing the property displayed by endo-brevicomin in experiment 1 (i.e., maximizing beetle response to an attractant when displaced a short distance from it, what we shall hereafter call "displacementenhanced synergism") could be interpreted in a challenge test to be either a synergist or an inhibitor depending solely upon the trap spacing used (Fig. 4). This is because challenge experiments employing a simultaneously-operated control trap cannot distinguish whether the test bait alters catch in the challenged trap rather than (or simultaneously with) the control trap. The ability to conclude enhancement or inhibitory activity in such tests relies on the assumption that traps are adequately spaced to assure that they cannot influence one another. However, the minimum separation required to assure trap independence is difficult to determine experimentally and has rarely been sought in research on bark beetle flight behavior (Dodds and Ross 2002). It should be noted that many of the interpretations of the results from the present study rely on the assumption that the minimum $100 \mathrm{~m}$ distance between adjacent experimental subjects (i.e., individual traps in experiment 1 , pairs in experiment 2 , and trios in experiments 3-4) was adequately large to prevent mutual interference.

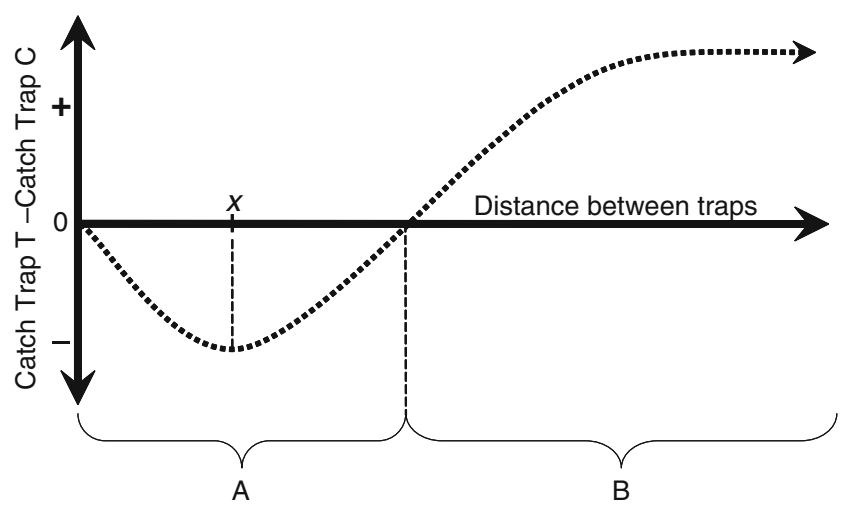

Fig. 4 Hypothetical responses of insects to two adjacent traps baited identically with an attractant where one trap chosen at random (treatment trap, "trap T") is baited additionally with a compound possessing the properties exhibited for (+)-endo-brevicomin in experiment 1 (Fig. 2), namely, it has (1) synergistic activity when attached directly to the trap and (2) maximum synergistic activity when displaced distance $x$ from the trap (i.e., displacement-enhanced synergism). The opposite trap ("trap C") is baited only with the attractant, and is thus equivalent to the control trap in a classic "attractant-challenge"-type trapping bioassay (see text). The Y-axis represents the arithmetic difference in catch between the two traps; the $\mathrm{X}$-axis represents the distance between the two traps. Within distance range $\mathrm{A}$, catch is greater in the control trap than the trap holding the experimental bait, and thus the "apparent" effect of the bait is inhibition. However, at greater distances (range B), catch is less in the control trap than the experimental trap, and the apparent effect of the bait is enhancement 
We suspect that interference among adjacent experimental traps compounded with endo-brevicomin's capacity for displacement-enhanced synergism may explain why many earlier studies failed to detect endo-brevicomin's synergistic activity. Intertrap spacing of less than $30 \mathrm{~m}$ is typical for studies evaluating bark beetle semiochemicals (Payne et al. 1978b; Bedard et al. 1980; Bakke 1981; Borden et al. 1987; Miller and Borden 1992; Sullivan 2005) and was 25 and $15-20 \mathrm{~m}$ in the only two trapping studies that both observed endo-brevicomin inhibition for $D$. frontalis and reported these experimental parameters (Payne et al. 1978a; Salom et al. 1992). Catch in the control traps of these tests was possibly enhanced by the nearby endo-brevicomin baits (i.e., attached to experimental traps) leading to the conclusion that the endo-brevicomin was reducing catch in the experimental trap to which it was attached. Experiment 1 demonstrated that endo-brevicomin can have synergistic effects on attractant-baited traps as far as $32 \mathrm{~m}$ away, hence greater trap spacing than this would be necessary to assure absence of intertrap effects. The two aforementioned studies were also performed within the limits of an active $D$. frontalis infestation, and endo-brevicomin released from naturally-infested trees within these infestations could likewise have altered responses to traps. One highly significant implication of our results is the possibility that additional bark beetle species possess pheromone components whose attractive activity has been overlooked due to the use of experimental procedures that concealed this activity.

Vité et al. (1985) demonstrated that the antipodes of endo-brevicomin elicited conflicting behavioral responses from $D$. frontalis, and they hypothesized that the inhibitory activity reported for endo-brevicomin in previous studies was due to the use of high release, racemic baits in which the antagonistic (-)-enantiomer overwhelmed the attractive $(+)$-enantiomer. In our experiment 2 , baits consisting either of two capillaries of racemic endo-brevicomin or of a single capillary of (+)-endo-brevicomin [and thus having an identical dose of $(+)$-endo-brevicomin but a differing dose of $(-)$ ] exhibited essentially identical activity (experiment 2 , Fig. 3). Thus, the (-)-enantiomer did not diminish the synergistic activity of the $(+)$-enantiomer at the release rates that we tested. Rather, experiment 2 demonstrated that both pure $(+)$ and racemic baits could induce greater catches in more distant traps, and thus either might appear to behave as an attractant synergist or inhibitor under appropriate experimental conditions (Fig. 4).

The mechanism that underlies displacement-enhanced synergism likely involves the concentration of the relevant components in the behavioral chemical plume, and displacement of a modifier compound (i.e., a synergist or an inhibitor) from an attractant-baited trap should influence pheromone concentrations within the plume downwind of the trap in predictable ways. These include: 1) the average concentration of the modifier within the attractant plume will be reduced, causing the active space of the combination (i.e., the zone in which both the attractant and modifier exceed the response threshold of the insect) to be smaller; 2) the relative proportions of the attractant and modifier will vary greatly within the overlapping portions of the plumes; and 3 ) the concentration of modifier at the attractant-baited trap and close to it will drop to zero unless the modifier is released directly upwind from the attractant (adapted from Byers 1987). Thus, reducing the modifier's release rate should at least partially duplicate the effects of displacing the modifier, particularly regarding effects 1 and 3 above. In support of this inference, spatial displacement of a modifier (either a synergist or an inhibitor) from the release point of an insect semiochemical generally produces the same outcome as reducing the dose of or eliminating the modifier: displacement of inhibitors increases (McLaughlin et al. 1974; Witzgall and Priesner 1991; Liu and Haynes 1992; Rumbo et al. 1993; Potting et al. 1999), whereas displacement of synergists reduces insect responses to a semiochemical (Linn and Gaston 1981; Byers 1987; Lux et al. 1994). However, in experiment 3, reducing the dose of $(+)$-endo-brevicomin at the center trap caused a reduction in $D$. frontalis catches at both the center and the adjacent traps, not an increase in catch at the center trap as would be predicted if the relatively higher catch in the outer traps was attributable simply to a relatively lower concentration of $(+)$-endo-brevicomin at these locations. Thus our data are not consistent with the hypothesis of an entirely dosedriven mechanism for the displacement-enhanced synergism of endo-brevicomin.

In addition to synergists and inhibitors, bark beetles may also utilize "multifunctional" semiochemicals that are attractive or synergistic at low release rates but inhibitory at high ones (Rudinsky 1973; Borden et al. 1987; Schlyter et al. 1987a; Seybold et al. 1992; Erbilgin et al. 2003). Furthermore, bark beetle responses to certain attractive semiochemicals decline at very high release rates (Seybold et al. 1992; Ross and Daterman 1998; Miller et al. 2005). Semiochemicals possessing such a parabolic dose-response curve should possess a single, optimally-attractive release rate; therefore the attractive activity of a bait exceeding this optimum dose could conceivably be enhanced by displacing it from the target (e.g., a trap), thereby effectively reducing its dose both at and downwind of the target. Additional experiments would be necessary to determine whether the (+)-enantiomer of endo-brevicomin produced by $D$. frontalis (Sullivan et al. 2007) has the parabolic dose-response of a multifunctional pheromone, however evidence suggests that at least racemic endo-brevicomin possesses this dynamic (Vité et al. 1985). Results of previous studies suggest that elevated doses of multifunctional pheromones may enhance insect attraction to or landing at distant locations. When 
Rabaglia and Lanier (1983) increased the rate that the multifunctional pheromone $\alpha$-multistriatin was released from the bole of host trees, landings by the European elm bark beetle, Scolytus multistriatus (Marsham), switched from the bole to the crown. Elevating the release rate of the multifunctional pheromone ipsdienol at a trap baited with aggregation pheromone increased the relative proportion of Ips typographus (L.) trapped in $3 \mathrm{~m}$-distant, unbaited traps while it increased the summed catch for all traps (Schlyter et al. 1987b). The possibility that displacement-enhanced synergism is a common property of multifunctional semiochemicals is worthy of further investigation. Enhanced knowledge of semiochemical plume dynamics in heterogeneous environments integrated with data from further studies that vary both the release rate and displacement of attraction modifiers will help to elucidate the mechanism underlying displacement-enhanced synergism.

Acknowledgments We thank Brad Hoosier, Joanne Barrett, Erich Vallery, Tessa Bauman, and Chris Young for technical assistance; Cavell Brownie for guidance on statistical analyses and addressing reviewers' comments; Drs. K. Fuhshuku and Y. Masuda of RIKEN, Japan, for help with the synthesis of (+)-endo-brevicomin; Lee Dunnam, Homochitto National Forest, MS, for assistance and cooperation in field studies; Rhonda Tam and Jessica Norris for administrative assistance; and Steve Clarke, Darrell Ross, and Will Shepherd for critical readings of earlier versions of this manuscript.

\section{References}

BAKKE, A. 1981. Inhibition of the response in Ips typographus to the aggregation pheromone; field evaluation of verbenone and ipsenol. Z. Angew. Entomol. 92:172-177.

Bedard, W. D., Wood, D. L., Tilden, P. E., Lindahl, K. Q. JR., and SilversteIn R. M. 1980. Field responses of the western pine beetle and one of its predators to host- and beetle-produced compounds. J. Chem. Ecol. 6:625-641.

Berryman, A. A. 1982. Population dynamics of bark beetles, pp. 264 314, in J. B. Mitton and K. B. Sturgeon (eds.). Bark beetles in North American conifers: A system for the study of evolutionary biology. University of Texas Press, Austin, TX.

Birgersson, G., and BergströM, G. 1989. Volatiles released from individual spruce bark beetle entrance holes: Quantitative variation during the first week of attack. J. Chem. Ecol. $15: 2465-2483$.

Birgersson, G., Schlyter, F., LÖFQvist, J., and Bergström, G. 1984. Quantitative variation of pheromone components in the spruce bark beetle Ips typopgraphus from different attack phases. J. Chem. Ecol. 10:1029-1055.

BORDEN, J. H. 1982. Aggregation pheromones, pp. 74-139, in J. B. Mitton and K. B. Sturgeon (eds.). Bark Beetles in North American Conifers: A System for the Study of Evolutionary Biology. University of Texas Press, Austin, TX.

BordEN, J. H. 1989. Semiochemicals and bark beetle populations: Exploitation of natural phenomena by pest management strategists. Holarct. Ecol. 12:501-510.

Borden, J. H., Ryker, L. C., Chong, L. J., Pierce, H. D. JR., Johnston, B. D., and Oehlschlager, A. C. 1987. Response of the mountain pine beetle, Dendroctonus ponderosae Hopkins
(Coleoptera: Scolytidae), to five semiochemicals in British Columbia lodgepole pine forests. Can. J. For. Res. 17:118-128.

Browne, L. E., Wood, D. L., Bedard, W. D., Silverstein, R. M., and WEST, J. R. 1979. Quantitative estimates of the western pine beetle attractive pheromone components, exo-brevicomin, frontalin, and myrcene in nature. J. Chem. Ecol. 5:397-414.

BYERS, J. A. 1987. Interactions of pheromone component odor plumes of western pine beetle. J. Chem. Ecol. 13:2143-2157.

Byers, J. A., Wood, D. L., Craig, J., and Hendry, L. B. 1984. Attractive and inhibitory pheromones produced in the bark beetle, Dendroctonus brevicomis, during host colonization: regulation of inter- and intraspecific competition. J. Chem. Ecol. 10:861-877.

COSTER, J. E., and GARA, R. I. 1968. Studies on the attack behavior of the southern pine beetle. II. response to attractive host material. Contrib. Boyce Thompson Inst. 24:69-75.

Coulson, R. N., Pulley, P. E., Foltz, J. L., and Martin, W. C. 1976. Procedural guide for quantitatively sampling within-tree populations of Dendroctonus frontalis. Texas Ag. Exp. Stn. Bull. Misc. Pub. MP-1287.

DoDDS, K. J. and Ross, D. W. 2002. Sampling range and range of attraction of Dendroctonus pseudotsugae pheromone-baited traps. Can. Entomol. 134:343-355.

ERBILGIN, N., POWELL, J. S., and RAFFA, K. F. 2003. Effect of varying monoterpene concentrations on the response of Ips pini (Coleoptera: Scolytidae) to its aggregation pheromone: Implications for pest management and ecology of bark beetles. Agric. For. Entomol. 5:269-274.

Fargo, W. S., Coulson, R. M., Pulley, P. E., Pope, D. N., and KeLlEY, C. L. 1978. Spatial and temporal patterns of within-tree colonization by Dendroctonus frontalis (Coleoptera: Scolytidae). Can. Entomol. 110:1213-1232.

Fettig, C. J., Dabney, C. P., Mckelvey, S. R., and Borys, R. R. 2006. An assessment of re-randomization methods in bark beetle (Scolytidae) trapping bioassays. Agric. For. Entomol. 8:267-271

GARA, R. I. 1967. Studies on the attack behavior of the southern pine beetle. I. The spreading and collapse of outbreaks. Contrib. Boyce Thompson Inst. 23:349-354.

GARA, R. I. and COSTER, J. E. 1968. Studies on the attack behavior of the southern pine beetle. III. Sequence of tree infestation within stands. Contrib. Boyce Thompson Inst. 24:77-85.

HugheS, P. R. 1976. Response of female southern pine beetles to the aggregation pheromone frontalin. Z. Angew. Entomol. 81:463466.

Johnson, P. C. and Coster, J. E. 1978. Probability of attack by southern pine beetle in relation to distance from an attractive host tree. Forest Sci. 24:574-580.

LAIDLAW, W. G. and WIESER, H. 2003. An effective strategy for trapping Douglas-fir beetle, Dendroctonus pseudotsugae (Col., Scolytidae) using combinations of unbaited and pheromone baited funnel traps. J. Appl. Entomol. 126:143-147.

LINN C. E. JR. and GASTON, L. K. 1981. Behavioral function of the components and the blend of the sex pheromone of the cabbage looper, Trichoplusia ni. Environ. Entomol. 10:751-755.

LIU, Y. -B. and HAYNES, K. F. 1992. Filamentous nature of pheromone plumes protects integrity of signal from background chemical noise in cabbage looper moth, Trichoplusia ni. J. Chem. Ecol. 18:299-307.

Lux, S. A., Hassanali, A., Lwande, W., and Nuogu, F. N. 1994. Proximity of release points of pheromone components as a factor confusing males of the spotted stem borer, Chilo partellus, approaching the trap. J. Chem. Ecol. 20:2065-2075.

Mclaughlin, J. R., Mitchell, E. R., Chambers, D. L., and Tumlinson, J. H. 1974. Perception of Z-7-dodecen-1-ol and modification of the sex pheromone response of male loopers. Environ. Entomol. 3:677-680. 
Miller, D. R. and Borden, J. H. 1992. (S)-(+)-Ipsdienol: Interspecific inhibition of Ips latidens (LeConte) by Ips pini (Say) (Coleoptera: Scolytidae). J. Chem. Ecol. 18:1577-1582.

Miller, D. R., Lindgren, B. S., and Borden, J. H. 2005. Dosedependent pheromone responses of mountain pine beetle in stands of lodgepole pine. Environ. Entomol. 34:1019-1027.

Nebeker, T. E., Hodges, J. D., KarR, B. K., and Moehring, D. M. 1985. Thinning practices in southern pines - with pest management recommendations. USDA For. Serv. Tech. Bull. 1703.

PAYNE, T. L. 1980. Life history and habits, pp. 31-54, in R. C. Thatcher, J. L. Searcy, J. E. Coster, and G. D. Hertel (eds.). The southern pine beetle. USDA Forest Service Sci. Ed. Admin. Tech. Bull. 1631.

Payne, T. L., Coster, J. E., Richerson, J. V., Edson, L. J., and HART, E. R. 1978a. Field response of the southern pine beetle to behavioral chemicals. Environ. Entomol. 7:578-582.

Payne, T. L., Coster, J. E., Richerson, J. V., Hart, E. R., Hedden, R. L., and EDSON, L. J. 1978b. Reducing variation in field tests of behavioral chemicals for the southern pine beetle. J. Georgia Entomol. Soc. 13:85-90.

Potting, R. P. J., Losel, P. M., and ScherkenBeck, J. 1999. Spatial discrimination of pheromones and behavioural antagonists by the tortricid moths Cydia pomonella and Adoxophyes orana. J. Comp. Physiol. A 185:419-425.

Pureswaran, D. S. and Borden, J. H. 2004. New repellant semiochemicals for three species of Dendroctonus (Coleoptera: Scolytidae). Chemoecology 14:67-75.

RABAGLIA, R. J. and LANIER, G. N. 1983. Effects of multilure components on twig-crotch feeding by European elm bark beetles. J. Chem. Ecol. 9:1513-1523.

ReEve, J. D. and Strom, B. L. 2004. Statistical problems encountered in trapping studies of scolytids and associated insects. J. Chem. Ecol. 30:1575-1590.

RENWICK, J. A. A. and ViTÉ, J. P. 1969. Bark beetle attractants: mechanism of colonization by Dendroctonus frontalis. Nature 224:1222-1223.

Renwick, J. A. A. and Vité, J. P. 1970. Systems of chemical communication in Dendroctonus. Contrib. Boyce Thomps. Inst. 24:283-292.

Ross, D. W. and Daterman, G. E. 1998. Pheromone-baited traps for Dendroctonus pseudotsugae (Coleoptera: Scolytidae): Influence of selected release rates and trap designs. J. Econ. Entomol. 91:500-506.

RUDINSKY, J. A. 1973. Multiple functions of the Douglas fir beetle pheromone 3-methyl-2-cyclohexen-1-one. Environ. Entomol. 2:579-585.
Rumbo, E. R., Deacon, S. M., and Regan, L. P. 1993. Spatial discrimination between sources of pheromone and an inhibitor by the light-brown apple moth Epiphyas postvittana (Walker) (Lepidoptera: Tortricidae). J. Chem. Ecol. 19:953-962.

Salom, S. M., Billings, R. F., Upton, W. W., Dalusky, M. J., Grosman, D. M., Payne, T. L., Berisford, C. W., and Shaver, T. N. 1992. Effect of verbenone enantiomers and racemic endobrevicomin on response of Dendroctonus frontalis (Coleoptera: Scolytidae) to attractant-baited traps. Can. J. For. Res. 22:925931.

SChlyter, F., Byers, J. A., and LÖFQvist, J. 1987a. Attraction to pheromone sources of different quantity, quality, and spacing: Density-regulation mechanisms in bark beetle Ips typographus. $J$. Chem. Ecol. 13:1503-1523.

SCHLYTER, F., LÖFQVIST, J., and BYERS, J. A. 1987b. Behavioural sequence in the attraction of the bark beetle Ips typographus to pheromone sources. Physiol. Entomol. 12:185-196.

Seybold, S. J., Teale, S. A., Wood, D. L., Zhang, A., Webster, F. X., LINDAHL, K. Q. JR., and KUBO, I. 1992. The role of lanierone in the chemical ecology Ips pini (Coleoptera: Scolytidae) in California. J. Chem. Ecol. 18:2305-2329.

Smith, M. T., Salom, S. M., and Payne, T. L. 1993. The southern pine bark beetle guild: an historical review of the research on the semiochemical-based communication system of the five principal species. Virginia Agricultural Experiment Station Bulletin 93-4.

SuLLIVAN, B. T. 2005. Electrophysiological and behavioral responses of Dendroctonus frontalis (Coleoptera: Curculionidae) to volatiles isolated from conspecifics. J. Econ. Entomol. 98:2067-2078.

Sullivan, B. T., Shepherd, W. P., Pureswaran, D. S., Tashiro, T., and MORI, K. 2007. Evidence that (+)-endo-brevicomin is a male-produced component of the southern pine beetle aggregation pheromone. J. Chem. Ecol. 33:1510-1527.

Tilden, P. E., BedARD, W. D., WoOd, D. L., Lindahl, K. Q. JR., and RAUCH, P. A. 1979. Trapping the western pine beetle at and near a source of synthetic attractive pheromone: Effects of trap size and position. J. Chem. Ecol. 5:519-531.

VITÉ, J. P. and RENwICK, J. A. A. 1971. Inhibition of Dendroctonus frontalis response to frontalin by isomers of brevicomin. Naturwissenschaften 8:418-419.

Vité, J. P., Billings, R. F., Ware, C. W., and Mori, K. 1985. Southern pine beetle: enhancement or inhibition of aggregation response mediated by enantiomers of endo-brevicomin. Naturwissenschaften 72:99.

WitZGALl, P. and PRIESNER, E. 1991. Wind-tunnel study on attraction inhibitor in male Coleophora laricella Hbn. (Lepidoptera: Coleophoridae). J. Chem. Ecol. 17:1355-1362. 